\title{
Future and present technologies of solid state lighting (Presentation Video)
}

\section{Shuji Nakamura}

Shuji Nakamura, "Future and present technologies of solid state lighting (Presentation Video)," Proc. SPIE 9383, Light-Emitting Diodes: Materials, Devices, and Applications for Solid State Lighting XIX, 93831M (27 April 2015); doi: 10.1117/12.2197203

SPIE. Event: SPIE OPTO, 2015, San Francisco, California, United States 


\title{
Future and present technologies of solid state lighting (Presentation Video)
}

\author{
Shuji Nakamura, University of California, Santa Barbara (USA)
}

\begin{abstract}
Blue nitride-based LEDs have been grown hetero-epitaxially on sapphire, SiC and Si substrates. Homo-epitaxial growth of LEDs grown on GaN substrate is getting popular to improve the reliability and to increase the power density per chip. Laser lighting also would be a promising lighting technology to improve the power density per chip in the future.
\end{abstract}

View presentation video on SPIE's Digital Library: http://dx.doi.org/10.1117/12.2197203.4078395318001 